\title{
Arsenic Detection with Porous Gold Microelectrode Prepared via Dynamic Soft Templating
}

\author{
Shunsuke Shiba* and Masanobu Matsuguchi \\ Department of Materials Science and Biotechnology, Graduate School of Science and Engineering, \\ Ehime University, 3-Bunkyo-cho, Matsuyama, Ehime 790-8577, Japan
}

(Received September 1, 2020; accepted September 30, 2020)

Keywords: arsenic, anodic stripping voltammetry, bicontinuous microemulsion, dynamic soft templating, porous microelectrode

A porous gold microelectrode $(\mu \mathrm{AuE})$ was fabricated by dynamic soft templating and used for the square-wave anodic stripping analysis of $\mathrm{As}(\mathrm{III})$. The porous $\mu \mathrm{AuE}$ was fabricated by the electrodeposition of $\mathrm{AuCl}_{4}{ }^{-}$dissolved in a bicontinuous microemulsion (BME), which has an intertwined three-dimensional network composed of aqueous and oil phases compartmentalized by a surfactant and a cosurfuctant, and acts as a dynamic soft template. A 41.5-fold increase in electrochemically active surface area (ECSA) was confirmed after electrodeposition, while the microelectrode characteristics were still observed. Cyclic voltammetry revealed that the porous $\mu \mathrm{AuE}$ has abundant $\mathrm{Au}\{100\}$ and/or kink/step sites compared with bare $\mu \mathrm{AuE}$. The overpotential for As(III) reduction decreased by $0.1 \mathrm{~V}$ at the porous $\mu \mathrm{AuE}$, which may be due to exposed $\mathrm{Au}$ facets. A limit of detection (LOD) of less than $5 \mathrm{ppb}$ and a wider linear range from 5 to $1000 \mathrm{ppb}$ were confirmed when using the porous $\mu \mathrm{AuE}$, which were due to the increased ECSA. In addition, the sensitivity at the porous $\mu \mathrm{AuE}$ was calculated to be $44.0 \mu \mathrm{A} \mathrm{cm}_{\text {geo }}^{-2} \mathrm{ppb}^{-1}, 14.4$ times higher than that at the bare $\mu \mathrm{AuE}$.

\section{Introduction}

Arsenic $[\mathrm{As}(\mathrm{III})]$ in rivers, soil, and drinking water is very harmful for both aquatic creatures and human beings because of its high toxicity and bioaccumulation in the body. Excessive intake of arsenic is known to induce various health problems including those of the skin, lungs, bladder, and kidneys. ${ }^{(1)}$ Therefore, the World Health Organization (WHO) has set the allowable arsenic concentration in natural water to below $10 \mathrm{ppb} .^{(2)}$

Arsenic mainly forms four oxidation states [As(-III), As(0), As(III), and As(V)]. Among them, As(III) is the most toxic substance and is commonly observed in natural water. There are various methods to analyze the concentration of As(III). Currently, the most reliable analytical methods are mass spectrometry (MS)-based methods including inductively coupled plasma mass spectrometry (ICP-MS). ${ }^{(3)}$ ICP-MS enables the detection of multiple metal species with a ppt-level limit of detection (LOD). However, it has some drawbacks such as high equipment and running costs, low throughput, the need for a skilled operator, and difficulty in on-site analysis.

*Corresponding author: e-mail: shiba.shunsuke.yu@ehime-u.ac.jp

https://doi.org/10.18494/SAM.2021.3068 
In contrast, electrochemical methods including anodic stripping voltammetry (ASV) have some advantages over the MS-based methods in terms of the above analytical characteristics. In ASV, As(III) dissolved in water is electrochemically reduced and concentrated on an electrode surface (generally $1-5 \mathrm{~min}$ ). Then, the electrode potential is swept in the positive direction to redissolve (strip) the deposited metals in a short time to obtain a large oxidation current. However, compared with other metal ions such as $\mathrm{Pb}(\mathrm{II})$ and $\mathrm{Cd}(\mathrm{II})$, the electrochemical detection of $\mathrm{As}(\mathrm{III})$ is difficult, mainly for two reasons. First, high overpotential is required to reduce the As(III) to As(0). This limits the applicable electrode materials, and a carbonbased electrode is not applicable because of its low electrocatalytic activity. Therefore, many researchers have recently focused on the exploration of highly electrocatalytic metal nanomaterials including gold nanoparticles, ${ }^{(4-8)}$ platinum nanoparticles, ${ }^{(9)}$ silver nanoparticles ${ }^{(10)}$ cobalt oxide nanoparticles, ${ }^{(1)}$ and nanostructured $\mathrm{MnO}_{\mathrm{x}}{ }^{(12)}$ Among them, $\mathrm{Au}$ is known to have higher affinity to As(III) deposition and stripping. ${ }^{(13)}$ The second reason is that the electron conductivity of the deposited $\operatorname{As}(0)$ is very low. Therefore, only one or two layers of $\mathrm{As}(0)$ can be concentrated on the electrode surface, although other metal ions including $\mathrm{Pb}(\mathrm{II})$ and $\mathrm{Cd}(\mathrm{II})$ can be electrodeposited even if the electrode surface is fully covered with the reduced metals. Such characteristics make it difficult to realize an LOD lower than $10 \mathrm{ppb}$ and a wide linear range.

To overcome this limitation, a microelectrode can be used to improve the LOD. Upon decreasing the electrode size down to micrometer order, the shape of the diffusion layer changes from linear to spherical, which enables the more efficient preconcentration of $\mathrm{As}(\mathrm{III})$ without the need to stir the solution. However, the linear range becomes narrower because the electrode surface area is very small compared with the surface area of a bulk electrode. In this regard, the formation of microelectrode arrays ${ }^{(13)}$ or a porous structure ${ }^{(14,15)}$ is an effective strategy to improve the linear range without sacrificing the advantages of the microelectrode behavior. In particular, the latter approach is more suitable because there is no need for lithographic techniques. Jaramillo et al. reported a nanoporous gold microelectrode $(\mu \mathrm{AuE})$ fabricated by a combination of anodization and electrochemical reduction. ${ }^{(14)}$ They realized a high sensitivity of $29.75 \mu \mathrm{A} \mathrm{cm}^{-2}$ geo $\mathrm{ppb}^{-1}$, a wide linear range of 2-200 ppb, and a low LOD of $0.62 \mathrm{ppb}$. Jiang et al. reported a nanoporous $\mu \mathrm{AuE}$ formed by dealloying, realizing an LOD of $20 \mathrm{nM}$ (equivalent to $1.5 \mathrm{ppb})$, a sensitivity of $13 \mathrm{nA} \mu \mathrm{M}^{-1}\left(0.975 \mu \mathrm{A} \mathrm{ppb}{ }^{-1}\right)$, and a linear range of $0.02-200 \mu \mathrm{M}$ (equivalent to $1.5-15 \mathrm{ppm}$ ).

Recently, we have developed a new synthesis methodology for a monolithic nanoporous gold film (NPGF) by using a bicontinuous microemulsion (BME) as a dynamic soft template. ${ }^{(16)}$ The BME forms three-dimensional intertwined networks of aqueous and oil channels on the order of less than $100 \mathrm{~nm}$, which are separated by a surfactant and a cosurfactant. Tetrachloroauric ions $\left(\mathrm{AuCl}_{4}\right)$, which are distributed in the aqueous phase in the BME, are electrodeposited on the sputtered gold film, providing a variety of nanostructure-controlled monolithic NPGFs. The electrochemical characterization revealed that the resultant films have a structure with many kinks and steps at the film surface, which is advantageous for electrocatalytic application. Here, we applied dynamic soft templating to prepare a porous $\mu \mathrm{AuE}$ to increase the electrochemically active surface area (ECSA) without losing the microelectrode characteristics. 


\section{Materials and Methods}

\subsection{Apparatus}

All the electrochemical experiments were performed using an electrochemical analyzer model, an ALS/CHI 1220B electrochemical analyzer (CH Instruments). A three-electrode configuration was set up throughout each experiment. A gold disk microelectrode ( $\mu \mathrm{AuE}$, i.d. $25 \mu \mathrm{m}$, BAS, Japan) and a Pt wire were used as the working and counter electrodes, respectively. Two reference electrodes, $\mathrm{Ag} / \mathrm{AgCl} \mid 3 \mathrm{M} \mathrm{NaCl}$ and $\mathrm{Hg} / \mathrm{Hg}_{2} \mathrm{SO}_{4} \mid$ sat. $\mathrm{K}_{2} \mathrm{SO}_{4}$ (BAS, Japan), were used. These electrodes satisfy the potential conversion equation $E(\mathrm{SHE})=E(\mathrm{Ag} / \mathrm{AgCl} \mid$ $3 \mathrm{M} \mathrm{NaCl})+195 \mathrm{mV}=E\left(\mathrm{Hg} / \mathrm{Hg}_{2} \mathrm{SO}_{4} \mid\right.$ sat. $\left.\mathrm{K}_{2} \mathrm{SO}_{4}\right)+675 \mathrm{mV}$. The potential difference between the $\mathrm{Ag} / \mathrm{AgCl}$ and $\mathrm{Hg} / \mathrm{Hg}_{2} \mathrm{SO}_{4}$ reference electrodes was around $480 \mathrm{mV}$, as confirmed by opencircuit potential measurement in $0.5 \mathrm{M} \mathrm{H}_{2} \mathrm{SO}_{4}$. The $\mathrm{Hg} / \mathrm{Hg}_{2} \mathrm{SO}_{4} \mid$ sat. $\mathrm{K}_{2} \mathrm{SO}_{4}$ is a chloride-ionfree reference electrode, the use of which prevents the dissolution of the Au electrode during anodic polarization in $0.5 \mathrm{M} \mathrm{H}_{2} \mathrm{SO}_{4}$ aqueous solution.

\subsection{Materials}

All chemicals were used without further purification. Arsenic standard solution (1000 ppm $\left.\mathrm{As}_{2} \mathrm{O}_{3}\right)$, tetrachloroaurate(III) tetrahydrate $\left(\mathrm{HAuCl}_{4} \cdot 4 \mathrm{H}_{2} \mathrm{O}, 99.9 \%\right)$, sodium dodecyl sulfate (SDS, 99.5\%), 2-methyl-2-butanol (2m2b), cyclohexane, hydrochloric acid ( $\mathrm{HCl}, 35.0-37.0 \%)$, sulfuric acid $\left(\mathrm{H}_{2} \mathrm{SO}_{4}, 95.0 \%\right)$, potassium chloride $(\mathrm{KCl})$, and potassium hexacyanoferrate (III) (ferricyanide) were purchased from Fujifilm Wako Pure Chemical (Japan). Ultrapure water was used in all the experiments.

\subsection{Preparation of BME solutions}

BME solution with a water/oil ratio of 53/47 (equally mixed BME) was prepared according to our previous report. ${ }^{(16)}$ Briefly, $0.40 \mathrm{~g}$ of SDS, $5.00 \mathrm{~mL}$ of $1 \mathrm{M} \mathrm{HCl}$ aqueous solution containing $50 \mathrm{mM} \mathrm{HAuCl}_{4}$, and $510 \mu \mathrm{L}$ of $2 \mathrm{~m} 2 \mathrm{~b}$ were mixed in a glass tube. Then, the mixture solution was ultrasonicated for $15 \mathrm{~min}$ to fully dissolve the SDS. Then, $5.00 \mathrm{~mL}$ of cyclohexane was added and mixed. After $3 \mathrm{~h}$ incubation at room temperature, three-phase solutions with a middle (bicontinuous) phase were formed with a water/oil ratio of 53/47 (equally mixed BME).

\subsection{Electrodeposition}

The $\mu \mathrm{AuE}$ was mechanically polished with $1 \mu \mathrm{m}$ alumina powder. Then, the three-electrode configuration was set up with $\mu \mathrm{AuE}$, the $\mathrm{Hg} / \mathrm{Hg}_{2} \mathrm{SO}_{4}$ electrode, and the $\mathrm{Pt}$ wire counter electrode in $0.5 \mathrm{M} \mathrm{H}_{2} \mathrm{SO}_{4}$ solution. Repeated cyclic voltammetry from -0.38 to $+1.12 \mathrm{~V}$ was performed at a scan rate of $50 \mathrm{mV} \mathrm{s}^{-1}$ to clean the electrode surface. Next, 1-1.5 mL of BME solution in the middle phase was gently extracted to the glass beaker. Then, we set up the threeelectrode configuration in a beaker with the cleaned $\mu \mathrm{AuE}, \mathrm{Ag} / \mathrm{AgCl}$ electrode, and $\mathrm{Pt}$ wire. 
After 15 min stabilization at room temperature, electrodeposition was carried out without stirring at $-0.20 \mathrm{~V}$ for $150 \mathrm{~s}$. After electrodeposition, we splashed the electrodeposited film with acetone and ethanol for $1 \mathrm{~min}$ and then dried it.

\subsection{Electrochemical characterization}

First, the three-electrode configuration with the working, counter, and $\mathrm{Hg} / \mathrm{Hg}_{2} \mathrm{SO}_{4}$ reference electrodes was set up in $0.5 \mathrm{M} \mathrm{H}_{2} \mathrm{SO}_{4}$. Repeated cyclic voltammetry for 10 cycles was performed to electrochemically clean the electrode and roughly investigate the exposed $\mathrm{Au}$ facets. Then, the ECSA was determined by the reduction charge of the monolayer Au oxide film formed in advance at $1.12 \mathrm{~V}$ for $300 \mathrm{~s}$ to ensure that the surface was fully oxidized, and then the potential was swept in the negative direction at a scan rate of $50 \mathrm{mV} \mathrm{s}^{-1}$ (linear sweep voltammetry, LSV). A conversion factor of $390 \mu \mathrm{C} \mathrm{cm}^{-2}$ was used to calculate ECSAs.

\subsection{Square-wave anodic stripping analysis of As(III)}

The $\mu \mathrm{AuE}$ electrode was transferred to an Ar-purged $1 \mathrm{M} \mathrm{HCl}$ aqueous solution in the presence or absence of an As(III) solution after the processes described in Sect. 2.4. The threeelectrode setup with $\mu \mathrm{AuE}$, the counter electrode, and the $\mathrm{Ag} / \mathrm{AgCl}$ electrode was used. Squarewave anodic stripping voltammetry (SWASV) was performed. The measurements consisted of three steps: (i) the electrochemical reduction of As(III) (preconcentration) without stirring the solution, (ii) square-wave anodic stripping from -0.20 to $+0.50 \mathrm{~V} \mathrm{vs} \mathrm{Ag} / \mathrm{AgCl}$ using a frequency $(f)$ of $15 \mathrm{~Hz}$, an amplitude $\left(E_{S w}\right)$ of $25 \mathrm{mV}$, and a step potential $\left(\Delta E_{S}\right)$ of $4 \mathrm{mV}$, and (iii) $30 \mathrm{~s}$ potential application at $+0.50 \mathrm{~V}$ to fully remove the remaining $\mathrm{As}(0)$ deposit from the gold surface.

\section{Results and Discussion}

\subsection{Investigation of the electrodeposition kinetics in equally mixed BME}

In our previous report, we optimized the electrodeposition potential in terms of the nanostructure and concluded that excessive negative potential $(-0.30 \mathrm{~V}$ vs $\mathrm{Ag} / \mathrm{AgCl})$ is required to form the NPGF on the sputtered Au film electrode. ${ }^{(16)}$ However, the electrochemical behavior of a microelectrode is generally different from that of a macroelectrode owing to the difference in the shape of the diffusion layer. To investigate the electrodeposition potential of $\mathrm{AuCl}_{4}{ }^{-}$on $\mu \mathrm{AuE}$, we conducted LSV in an equally mixed BME containing $50 \mathrm{mM} \mathrm{AuCl}{ }_{4}^{-}$ (Fig. 1). The reduction current started to flow at the onset potential of $+0.68 \mathrm{~V}$ vs $\mathrm{Ag} / \mathrm{AgCl}$, which corresponds to the electrochemical reduction of $\mathrm{AuCl}_{4}{ }^{-}$. The observed electrodeposition potential was the same as that previously reported. ${ }^{(16)}$ However, the microelectrode exhibited electrochemical behavior below $+0.68 \mathrm{~V}$ that was different from that of the macroelectrode. In the case of the macroelectrode, a reduction peak current was observed and the reduction current after the peak potential was almost constant. In contrast, in the case of $\mu \mathrm{AuE}$, no peak was observed and the reduction current did not become constant and gradually increased with 


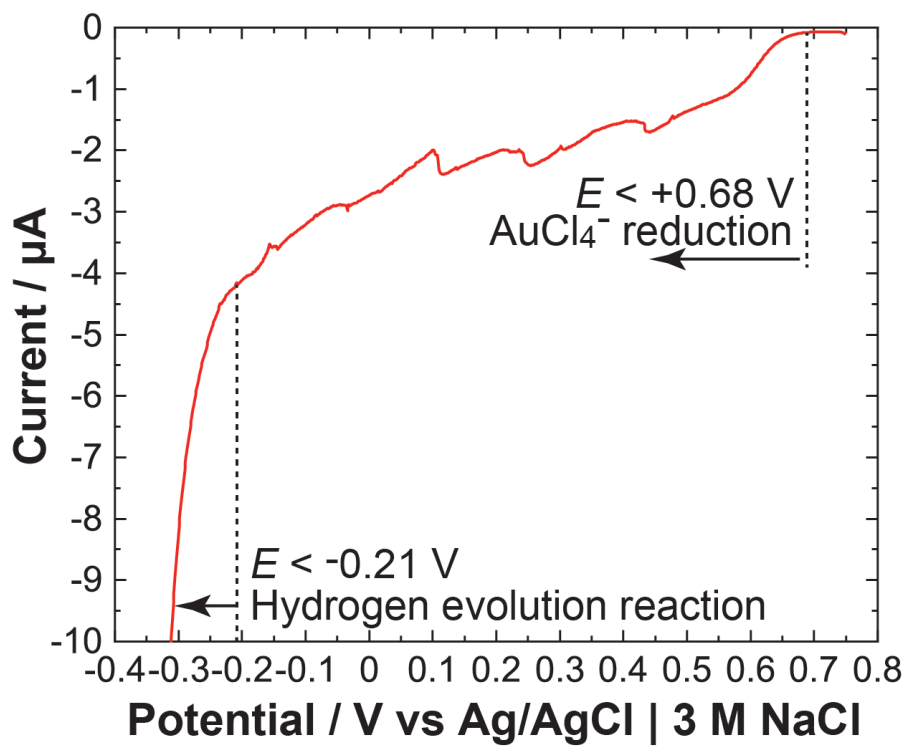

Fig. 1. (Color online) Linear sweep voltammograms in equally mixed BME obtained with polished $\mu$ AuE (scan rate: $5 \mathrm{mV} \mathrm{s}^{-1}$ ). The $\mathrm{pH}$ of the aqueous solution (1 M HClaq) is 0.36 .

decreasing electrode potential. These differences are due to the fact that the electrodeposition is not diffusion-controlled because of the small area of $\mu \mathrm{AuE}$. The gradually increasing reduction current may be due to the increase in electrode area during LSV. In addition, a sharp reduction current was observed at the onset potential of $-0.21 \mathrm{~V}$, which corresponds to the hydrogen evolution reaction (HER). The observed potential of the HER was more positive than that observed with a sputtered Au film macroelectrode. ${ }^{(16)}$ This may also be ascribed to the different diffusion processes of $\mathrm{AuCl}_{4}{ }^{-}$during LSV, which might result in the formation of a different nanostructure with higher electrocatalytic activity toward the HER. Although the electrodeposition potential optimized in the previous report was $-0.30 \mathrm{~V}^{(16)}$ here we ensured that the electrodeposition potential was $-0.20 \mathrm{~V}$ to inhibit the competitive reactions of $\mathrm{AuCl}_{4}{ }^{-}$ reduction and the HER.

\subsection{Electrochemical characterization of porous $\mu \mathrm{AuE}$}

We conducted the surface characterization of the porous $\mu \mathrm{AuE}$ with and without $\mathrm{AuCl}_{4}{ }^{-}$ electrodeposition (electrodeposition time, 200 s) to investigate the ECSA, exposed Au facets, and microelectrode characteristics. Figure 2 shows the negatively swept linear sweep voltammograms after applying $+1.12 \mathrm{~V}$ vs $\mathrm{Hg} / \mathrm{Hg}_{2} \mathrm{SO}_{4} \mid \mathrm{sat} . \mathrm{K}_{2} \mathrm{SO}_{4}$ to realize a fully oxidized gold surface. The ECSA was determined by the reduction charge of monolayer Au oxide with a conversion factor of $390 \mu \mathrm{C} \mathrm{cm}^{-2}$. The calculated ECSA of the porous $\mu A u E$ was $8.99 \times 10^{-4} \mathrm{~cm}^{2}$ (reduction peak charge, $0.347 \mu \mathrm{C}$ ), which is 41.5 times larger than that of $\mu \mathrm{AuE}$ without electrodeposition $\left(2.14 \times 10^{-5} \mathrm{~cm}^{2}, 8.34 \mathrm{nC}\right)$. This indicates that the electrodeposit formed a highly porous structure. The ratio of the ECSA before and after electrodeposition 


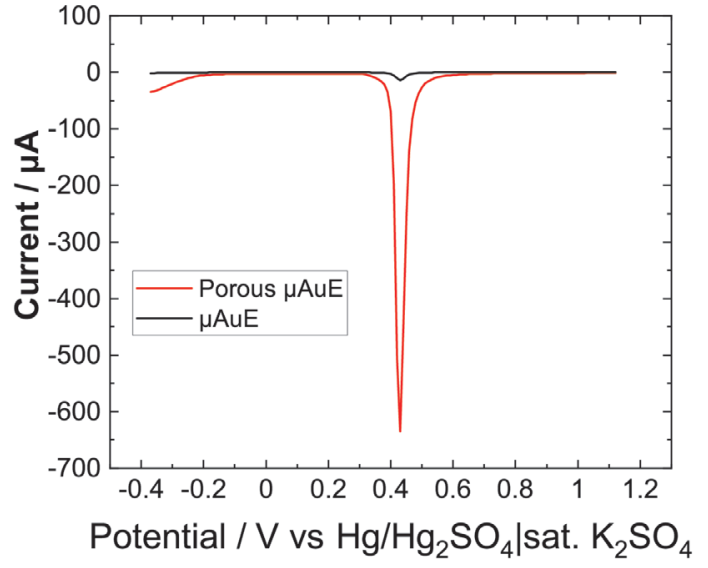

(a)

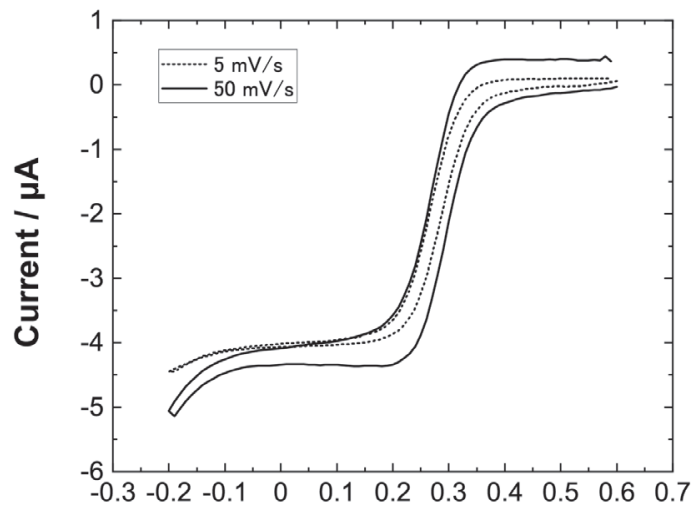

Potential / V vs Ag/AgCl | $3 \mathrm{M} \mathrm{NaCl}$

(c)

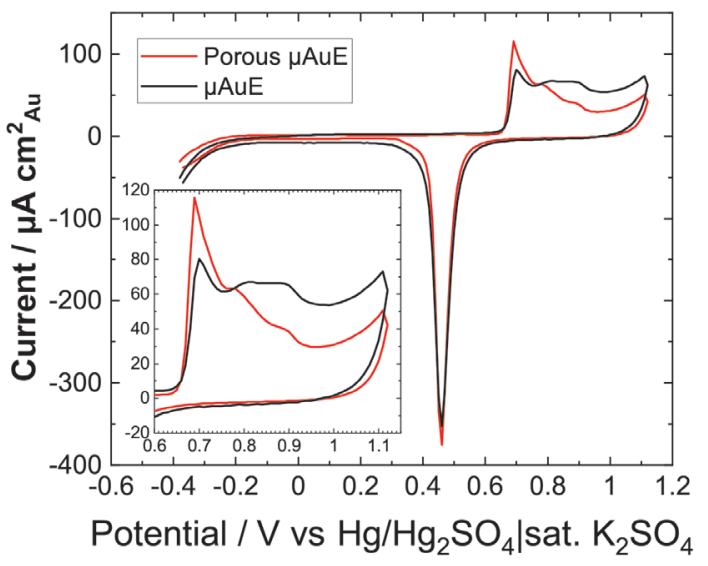

(b)

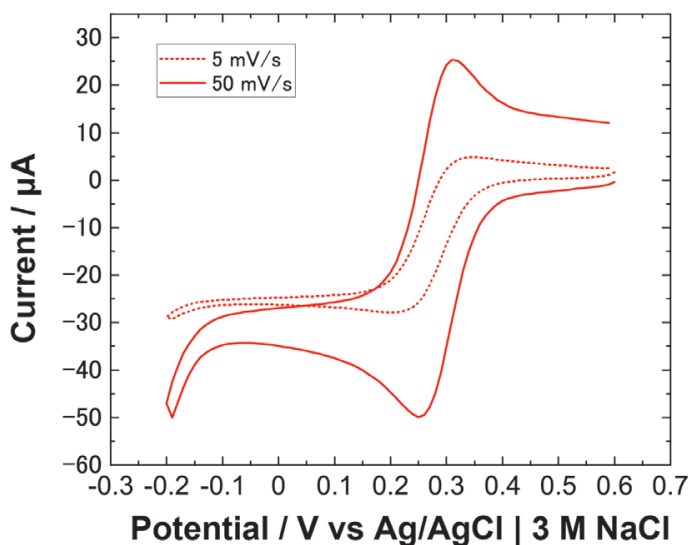

(d)

Fig. 2. (Color online) (a) Linear sweep voltammogram used to estimate electrochemically active surface area (ECSA) before (black) and after (red) electrodeposition. The potential was negatively swept after the application of $+1.12 \mathrm{~V}$ for $300 \mathrm{~s}$ to obtain a fully oxidized Au surface. (b) Tenth cyclic voltammograms (CVs) obtained with $\mu$ AuE before (black) and after (red) electrodeposition. The inset shows magnified CVs. Supporting electrolyte: $0.5 \mathrm{M} \mathrm{H}_{2} \mathrm{SO}_{4}$ aqueous solution. (c, d) CVs of $1 \mathrm{mM}$ ferricyanide in $1.0 \mathrm{M} \mathrm{KCl}$ at (c) bare and (d) porous $\mu$ AuEs.

is much larger than that in the case of using a sputtered $\mathrm{Au}$ film macroelectrode reported previously. ${ }^{(16)}$ This is probably due to the growth of spherical porous Au. Note that there is no evidence to conclude the formation of a "nanoporous" electrode since we did not conduct scanning electron microscopy (SEM). However, the existence of abundant porosity is assured because of the much greater increase in ECSA.

Figure 2(b) shows the 10th CVs obtained with $\mu \mathrm{AuE}$ with or without electrodeposition in $0.5 \mathrm{M} \mathrm{H}_{2} \mathrm{SO}_{4}$. Note that the $y$-axis is normalized by the ECSA for comparison. It is known that the oxidation potentials of $\mathrm{Au}$ atoms differ with the coordination number and the presence of exposed $\mathrm{Au}$ facets. ${ }^{(17-20)}$ In other words, the oxidation current curve at the polycrystalline $\mathrm{Au}$ electrode can be deconvoluted into several curves, each of which has a specific peak oxidation potential determined by the experimental results obtained using a single-crystalline $\mathrm{Au}$ 
electrode. Therefore, the comparison of ECSA-normalized current densities at each potential enables the ratio of exposed $\mathrm{Au}$ facets at the electrode surface to be roughly estimated. In the case of bare $\mu \mathrm{AuE}$ without electrodeposition, there are some peaks including a small sharp peak current at around $+0.70 \mathrm{~V}$ vs $\mathrm{Hg} / \mathrm{Hg}_{2} \mathrm{SO}_{4}(+1.18 \mathrm{~V}$ vs $\mathrm{Ag} / \mathrm{AgCl})$, broad peaks at $+0.80 \mathrm{~V}$ vs $\mathrm{Hg}$ / $\mathrm{Hg}_{2} \mathrm{SO}_{4}(+1.28 \mathrm{~V}$ vs $\mathrm{Ag} / \mathrm{AgCl})$ and $+0.90 \mathrm{~V}$ vs $\mathrm{Hg} / \mathrm{Hg}_{2} \mathrm{SO}_{4}(+1.38 \mathrm{~V}$ vs $\mathrm{Ag} / \mathrm{AgCl})$, and a broad oxidation current in the potential region of more than $0.90 \mathrm{~V} \mathrm{vs} \mathrm{Hg} / \mathrm{Hg}_{2} \mathrm{SO}_{4}$, which correspond to $\mathrm{Au}\{100\}$ and/or kink/step sites, $\mathrm{Au}\{110\}$ facets, and $\mathrm{Au}\{111\}$ facets, respectively. In contrast, the porous $\mu \mathrm{AuE}$ shows a much larger sharp peak current at $0.70 \mathrm{~V}$ vs $\mathrm{Hg} / \mathrm{Hg}_{2} \mathrm{SO}_{4}$ and smaller oxidation currents at the other potentials described above. These findings indicate that the electrodeposition in the equally mixed BME provides abundant $\mathrm{Au}\{100\}$ and/or kink/step sites, the tendency of which is in good agreement with that reported previously. ${ }^{(16)}$

Figures 2(c) and 2(d) show the CVs of ferricyanide, used to determine whether the microelectrode characteristics are maintained after electrodeposition. As shown in Fig. 2(c), the bare $\mu \mathrm{AuE}$ provides a redox current with a sigmoidal shape at scan rates of both 5 and $50 \mathrm{mV} \mathrm{s}^{-1}$, which is a typical response of a microelectrode. In the case of the porous $\mu \mathrm{AuE}$, a similar sigmoidal response was observed when the scan rate was $5 \mathrm{mV} \mathrm{s}^{-1}$. Therefore, we considered that, even after electrodeposition, the microelectrode features were not lost. However, the limiting current of ferricyanide reduction at $5 \mathrm{mV} \mathrm{s}^{-1}$ is around $25 \mathrm{nA}$, which is about six times larger than that at the bare $\mu \mathrm{AuE}$. Jiang et al. reported that limiting currents of $10 \mathrm{mM}$ ferricyanide obtained with the bare and porous $\mu$ AuEs at $2 \mathrm{mV} \mathrm{s}^{-1}$ were similar, although the latter had a 25 times higher ECSA than the former. ${ }^{(21)}$ Their porous $\mu$ AuE was fabricated by a top-down dealloying approach that did not change the geometric area of the electrode. In contrast, we used a bottom-up electrodeposition approach. Therefore, we speculate that the three-dimensional bottom-up growth of the electrode surface resulted in the increase in the geometric area of the electrode, which may lead to a higher reduction rate of ferricyanide. When sweeping the potential at the scan rate of $50 \mathrm{mV} \mathrm{s}^{-1}$, a couple of oxidation and reduction peaks were observed. This clearly indicates that the formation of the porous structure provides abundant electrochemically active sites that enhance the electrochemical redox reaction of ferricyanide.

\subsection{Optimization of deposition potential of As(III)}

We conducted SWASV measurements of $20 \mathrm{ppb}$ As(III) dissolved in $1 \mathrm{M} \mathrm{HCl}$ while changing the deposition potential. Note that the solution was not stirred. Figure 3 shows the dependence of the electrodeposition potential on the peak current. In the case of the bare $\mu \mathrm{AuE}$ (black open squares), the stripping peak current was observed at a potential below $-0.05 \mathrm{~V}$ vs $\mathrm{Ag} / \mathrm{AgCl}$, and the current observed below $-0.20 \mathrm{~V}$ vs $\mathrm{Ag} / \mathrm{AgCl}$ was almost constant. These results indicate that sufficient electron transfer rates were assured below $-0.20 \mathrm{~V}$ vs $\mathrm{Ag} / \mathrm{AgCl}$. Interestingly, in the case of the porous $\mu \mathrm{AuE}$ (red open circles), larger stripping currents were observed below $+0.05 \mathrm{~V}$, which is a more positive potential than that for the bare $\mu \mathrm{AuE}$. This implies that the abundant $\mathrm{Au}\{100\}$ and/or kink/step sites may contribute to decreasing the overpotential of the As(III) reduction reaction. 


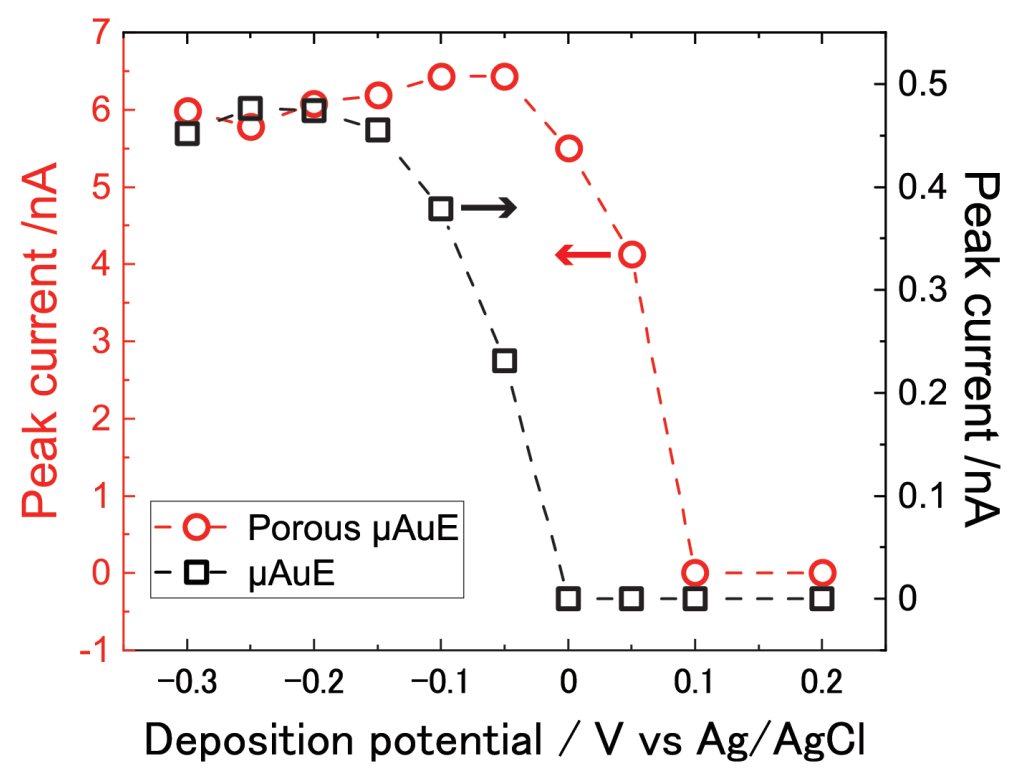

Fig. 3. (Color online) Dependence of deposition potential $\left(E_{d}\right)$ on the square-wave anodic stripping peak current obtained by bare $\mu \mathrm{AuE}$ (black open squares) and porous $\mu \mathrm{AuE}$ (red open circles). Supporting electrolyte: $1 \mathrm{M} \mathrm{HCl}$ aqueous solution. SWASV parameters: $E_{d e p}=-0.20 \mathrm{~V}, t_{d e p}=180 \mathrm{~s}, f=15 \mathrm{~Hz}, E_{s w}=25 \mathrm{mV}$, and $\Delta E_{S}=4 \mathrm{mV}$.

\subsection{Calibration curves}

On the basis of the results described in Sect. 3.3, we adopted $-0.20 \mathrm{~V}$ vs $\mathrm{Ag} / \mathrm{AgCl}$ as the deposition potential of As(III) at both electrodes for comparison. Figure 4 shows the SWASV curves obtained with the (a) bare and (b) porous $\mu$ AuEs. In both cases, the stripping peak current was obtained at $+0.13 \mathrm{~V}$, implying that the stripping potential of $\mathrm{As}(0)$ is not dependent on the exposed facets. Since the obtained current at the bare $\mu \mathrm{AuE}$ was less than $4 \mathrm{nA}$ even in the presence of $1000 \mathrm{ppb} \mathrm{As}(\mathrm{III})$, this current was very noisy. This makes it difficult to detect a trace amount of As(III), particularly a concentration of $5 \mathrm{ppb}$. In contrast, in the case of the porous $\mu \mathrm{AuE}$, a much larger stripping current was obtained. Therefore, $5 \mathrm{ppb} A s(\mathrm{III})$ was clearly detected as shown in the inset in Fig. 4(b). Figure 4(c) shows the calibration curves. In the case of the bare $\mu \mathrm{AuE}$, the linearity was obtained between concentrations of 5 and $50 \mathrm{ppb}$ $\left(R^{2}=0.998\right)$. However, as shown in the magnified inset graph, the stripping current tended to saturate over $100 \mathrm{ppb}$ owing to the low ECSA of the bare $\mu \mathrm{AuE}$. In contrast, high linearity $\left(R^{2}=0.998\right)$ from 5 to $1000 \mathrm{ppb}$ was confirmed when using the porous $\mu \mathrm{AuE}$. The sensitivity

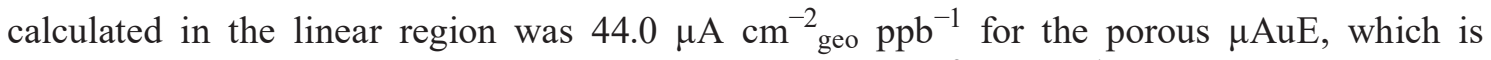
14.4 times larger than that of the bare $\mu \mathrm{AuE}\left(3.06 \mu \mathrm{A} \mathrm{cm}^{-2}\right.$ geo $\left.\mathrm{ppb}^{-1}\right)$. Taking these findings together, we concluded that the porous $\mu \mathrm{AuE}$ with increased ECSA fabricated by dynamic soft templating contributes to realizing a higher sensitivity and a wider linear range while maintaining (or improving) the LOD at less than $5 \mathrm{ppb}$. 


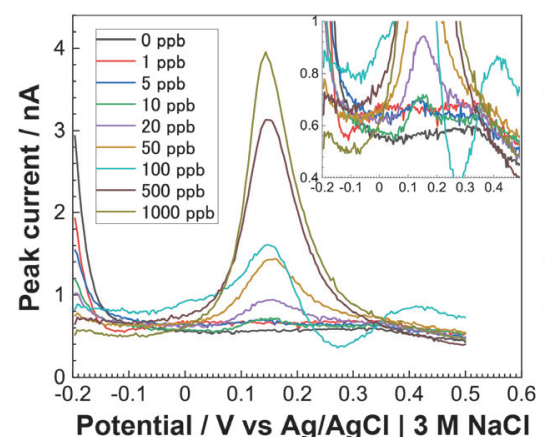

(a)

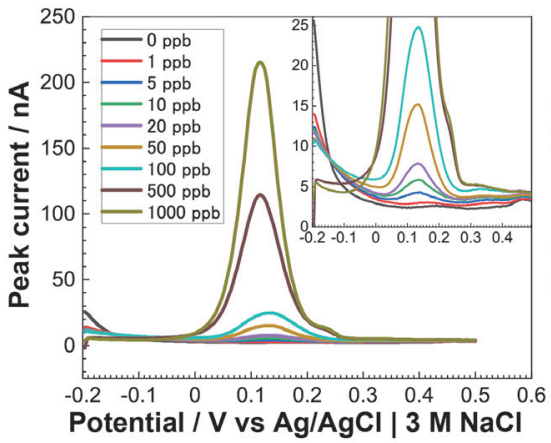

(b)

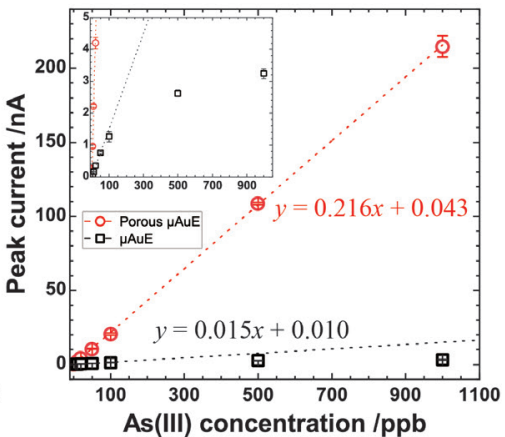

(c)

Fig. 4. (Color online) SWASV curves for various concentrations of As(III) obtained with (a) bare and (b) porous $\mu$ AuEs. The inset shows magnified SWASV curves. (c) Calibration plots (peak current height vs As(III) concentration) obtained with bare $\mu \mathrm{AuE}$ (black open squares) and porous $\mu \mathrm{AuE}$ (red open circles). Supporting electrolyte: $1 \mathrm{M} \mathrm{HCl}$ aqueous solution. SWASV parameters: $E_{d e p}=-0.20 \mathrm{~V}, t_{d e p}=120 \mathrm{~s}, f=15 \mathrm{~Hz}, E_{s w}=25 \mathrm{mV}$, and $\Delta E_{S}=4 \mathrm{mV}$.

\section{Conclusions}

We applied our recently developed dynamic soft templating method to fabricate a porous $\mu \mathrm{AuE}$. The electrodeposition at $-0.20 \mathrm{~V}$ for $150 \mathrm{~s}$ in the BME containing $50 \mathrm{mM} \mathrm{AuCl}_{4}{ }^{-}$ provided a porous $\mu \mathrm{AuE}$ with an ECSA of $8.99 \times 10^{-4} \mathrm{~cm}^{2}$, which is 41.5 times larger than that of bare $\mu \mathrm{AuE}$. Interestingly, $\mathrm{As}(\mathrm{III})$ molecules start to be reduced below $+0.05 \mathrm{~V}$ at the porous $\mu \mathrm{AuE}$, which is $0.10 \mathrm{~V}$ more positive than that at the bare $\mu \mathrm{AuE}$. This difference in overpotential may be ascribed to the difference in the surface structure of gold, such as exposed $\mathrm{Au}$ facets, and/or nanosize effects. Owing to the above structural characteristics, the porous $\mu \mathrm{AuE}$ shows a 14.4 times higher sensitivity $\left(44.0 \mu \mathrm{A} \mathrm{cm}^{-2}\right.$ geo $\left.\mathrm{ppb}^{-1}\right)$ and a wider linear range (5-1000 ppb) than the bare $\mu \mathrm{AuE}$ and has an LOD of less than $5 \mathrm{ppb}$, which is lower than the value of $10 \mathrm{ppb}$ recommended by WHO. We thus successfully demonstrated that our developed dynamic soft templating method is effective for realizing a porous microelectrode for metal ion detection without stirring the sample solution.

\section{Acknowledgments}

This work was supported by Kurita Water and Environmental Foundation Grant Number 19E008.

\section{References}

1 H. Li and R. B. Smart: Anal. Chim. Acta 325 (1996) 25. https://doi.org/10.1016/0003-2670(96)00011-6

2 World Health Organization: Fact Sheet No. 210 (May 2001).

3 N. Zhang, K. Shen, X. Yang, Z. Li, T. Zhou, Y. Zhang, Q. Sheng, and J. Zheng: Food Chem. 264 (2018) 462. https://doi.org/10.1016/j.foodchem.2018.05.058 
4 D. Kato, T. Kamata, D. Kato, H. Yanagisawa, and O. Niwa: Anal. Chem. 88 (2016) 2944. https://doi. org/10.1021/acs.analchem.6b00136

5 M. G. Trachioti, A. E. Karantzalis, J. Hrbac, and M. I. Prodromidis: Sens. Actuators, B 281 (2019) 273. https:// doi.org/10.1016/j.snb.2018.10.112

6 A. Buffa and D. Mandler: Electrochim. Acta 318 (2019) 496. https://doi.org/10.1016/j.electacta.2019.06.114

7 D. Lu, C. Sullivan, E. M. Brack, C. P. Drew, and P. Kurup: Anal. Bioanal. Chem. 412 (2020) 4113. https://doi. org/10.1007/s00216-020-02642-4

8 C. Sullivan, D. Lu, E. Brack, C. Drew, and P. Kurup: Anal. Chim. Acta 1107 (2020) 63. https://doi.org/10.1016/ j.aca.2020.02.015

9 W. B. Postek, I. A. Rutkowska, J. A. Cox, and P. J. Kulesza: Electrochim. Acta 319 (2019) 499. https://doi. org/10.1016/j.electacta.2019.06.144

10 K. Torres-Rivero, C. Pérez-Ràfols, J. Bastos-Arrieta, A. Florido, V. Martí, and N. Serrano: Nanomaterials 10 (2020) 1. https://doi.org/10.3390/nano10071280

11 A. Salimi, H. Mamkhezri, R. Hallaj, and S. Soltanian: Sens. Actuators, B 129 (2008) 246. https://doi. org/10.1016/j.snb.2007.08.017

12 T. Gupte, S. K. Jana, J. S. Mohanty, P. Srikrishnarka, S. Mukherjee, T. Ahuja, C. Sudhakar, T. Thomas, and T. Pradeep: ACS Appl. Mater. Inter. 11 (2019) 28154. https://doi.org/10.1021/acsami.9b06023

13 R. Feeney and S. P. Kounaves: Anal. Chem. 72 (2000) 2222. https://doi.org/10.1021/ac991185z

14 D. X. O. Jaramillo, A. Sukeri, L. P. H. Saravia, P. J. Espinoza-Montero, and M. Bertotti: Electroanalysis 29 (2017) 2316. https://doi.org/10.1002/elan.201700301

15 L. Chao, X. J. Xiong, J. Liu, A. G. Xu, T. Huang, F. He, and Q. J. Xie: Sens. Actuators, B 253 (2017) 603. https://doi.org/10.1016/j.snb.2017.06.150

16 S. Shiba, S. Hirabayashi, O. Niwa, D. Kato, M. Kunitake, and M. Matsuguchi: ACS Appl. Nano Mater. 3 (2020) 7750. https://doi.org/10.1021/acsanm.0c01316

17 Z. Wang, P. Liu, J. Han, C. Cheng, S. Ning, A. Hirata, T. Fujita, and M. Chen: Nat. Commun. 8 (2017). https:// doi.org/10.1038/s41467-017-01085-3

18 A. Hamelin: J. Electroanal. Chem. 407 (1996) 1. https://doi.org/10.1016/0022-0728(95)04499-X

19 T. Kondo, J. Morita, K. Hanaoka, S. Takakusagi, K. Tamura, M. Takahasi, J. Mizuki, and K. Uosaki: J. Phys. Chem. C 111 (2007) 13197. https://doi.org/10.1021/jp072601j

20 F. S. Ke, B. Solomon, Y. Ding, G. L. Xu, S. G. Sun, Z. L. Wang, and X. D. Zhou: Nano Energy 7 (2014) 179. https://doi.org/10.1016/j.nanoen.2014.01.003

21 J. H. Jiang, X. Y. Wang, and L. Zhang: Electrochim. Acta 111 (2013) 114. https://doi.org/10.1016/ j.electacta.2013.07.196 